\title{
Functional Outcomes of Surgical Management for Spinal Epidural Masses in an Egyptian Tertiary Hospital
}

Amr Mostafa Elkatatny ${ }^{1^{*}}$, Hossam Eldin Mostafa ${ }^{1}$, Ahmad H. Gouda ${ }^{1}$, Mohamed Abdeltawab Mahmoud ${ }^{1}$, Dina Mahmoud Alnajjar ${ }^{2}$, Dina Abdelazim Ghoraba

${ }^{1}$ Department of Neurosurgery, Kasralainy School of Medicine and University Hospitals, Cairo University, Cairo, Egypt; ${ }^{2}$ Department of Diagnostic Radiology, Kasralainy School of Medicine and University Hospitals, Cairo University, Cairo, Egypt

Citation: Elkatatny AM, Mostafa HE, Gouda AH Mahmoud MA, Alnaijar DM, Ghoraba DA. Functiona Outcomes of Surgical Management for Spinal Epidura Masses in an Egyptian Tertiary Hospital. Open Acces Maced J Med Sci. 2019 Sep $15 ; 7(17): 2829-2837$
https://doi.org/10.3889/oamjms.2019.575 Keywords: Spinal epidural mass; Microsurgical resection; Neurosurgery: Functional Outcome *Correspondence: Amr Mostafa Elkatatny. Departmen University Hospitals, Cairo University, Cairo, Egypt. mail: amramostafa2013@gmail.com

Received: 21-Mar-2019; Revised: 14-Jut-2019; Received: 21-May-2019, Revised: 14-Jul-2019; Copyright: () 2019 Amr Mostafa Elkatatny, Hossam ldin Mostafa, Ahmad H. Gouda, Mohamed Abdeltawa Ghoraba. This is an open-access article distributed under the terms of the Creative Commons AtributionNonCommercial 4.0 International License (CC BY-NC 4.0) Funding: This research did not receive any financial

Competing Interests: The authors have declared that no competing interests exist

\section{Abstract}

BACKGROUND: The spinal epidural space, covering the dural sac, is located along the posterior longitudina ligament anteriorly, the ligamentum flavum and the periosteum of laminae posteriorly, and the pedicles of the spinal column by the intervertebral foramina containing their neural elements laterally. It could be affected variably by different types of diseases, either as primary lesions or as an extension from a disease process in the nearby tissues and organs.

AIM: We aimed to present clinically and surgically patients with spinal epidural masses operated in the Neurosurgery Department of Cairo University Hospitals, Cairo, Egypt, along a time interval of one year.

METHODS: In this prospective cohort study, we analysed motor deficits, sensory deficits, and bowel and bladde dysfunction. We have performed decompressive laminectomy on 19 patients with spinal epidural masses together with mass excision as long as the tumour was accessible, with or without fixation.

RESULTS: All patients were radiologically assessed by MRI over the affected side of the spine. D10 was the commonest site in our study to be affected in 10 cases of our participants (23\%), followed by D5, D7, and D12 each of them was affected in 6 cases (14\%), in another word spinal segments by order of frequency to be affected were dorsal followed by lumbar spine. All patients included in this study $(100 \%)$ showed an obvious improvement as regard pain and tenderness.

CONCLUSION: Surgical interventions have improved the quality of life for our patients with spinal epidural masses.

\section{Introduction}

Spinal Epidural Space is a space between the dura and the ligamentum flavum and periosteum of the vertebral bodies, pedicles and laminae. Spinal epidural space pathologies, both intrinsic and extrinsic to the epidural space have been described in scattered articles in literature [1].

In this prospective cohort study, we will report a one--year surgical experience in managing 44 patients with different types of epidural spinal masses, presented at the Department of Neurosurgery in Kasralainy Medical School Teaching Hospitals, Cairo, Egypt, regarding motor deficits, sensory deficits, bowel and bladder dysfunction.

\section{Methods}

\section{Patients}

In this study, we clinically and surgically evaluated 44 patients with spinal epidural masses. All patients were operated in the Neurosurgery Department of Cairo University Hospitals, Cairo, Egypt, along a time interval of one year. We followed very strict criteria in selecting our candidates from the patients who were suffering spinal epidural masses which resulted in neurological deficits.

Inclusion criteria were patients indicated for surgical management for unknown primary tissue diagnosis, spinal instability or deficits, Radio -resistant tumours, recurrence after maximal XRT 
and rapid neurologic deterioration. Exclusion criteria included patients with very radiosensitive tumours, total paralysis, expected survival $<3-4$ months, multiple lesions at different spinal levels and the inability to tolerate the surgery.

\section{Data Collection}

All candidates provided the necessary data fulfilling our study protocol and were investigated clinically prior surgical interventions than were maintained on a scheduled post-operative follow-up visits.

A) History Taking: Age, gender, occupation, time of initial complaint till the time of presentation, history of any type of cancer that the patient suffered from, history of co-morbidities, e.g. diabetes mellitus, smoking, history of previous operations and history of tuberculosis or anti -tuberculosis treatment.

B) Clinical Examination: All patients were clinically evaluated and examined with special care to the following signs and symptoms: low back pain, motor deficit, sensory deficit, sphincteric deficit, upper motor neuron (UMN) manifestations in case of cervical, thoracic, or upper lumbar lesions and lower motor neuron (LMN) manifestations in the lower lumbar manifestations.

C) Radiological Investigations: Cervical, thoracic, lumbar and sacral spine X-ray: anteroposterior, lateral and stress views (flexion. extension) were done with the emphasis on the signs of instability (in stress views).

1) Computed Tomography of the spine: For assessing the bony spines and the ability of instrumental fixation.

2) Cervical, thoracic and lumbosacral MRI (with contrast): To detect possible pathological abnormalities and for feasible interventions.

D) Management: All patients were indicated for surgery; we emphasised on certain points for the study design:

\section{1) Any history of the previous operation}

2) Type of the selected operation:

- Cervical spine: Posterior laminectomy, lateral mass fixation, anterior corpectomy or anterior plate placement.

- Thoracic spine: Usually, circumferential fixation was done.

- Lumbosacral spine: Decompressive laminectomy and transpedicular fixation, Intra -operative cause of neural compression;

- Intra-operative findings of Abscess, pott's disease, neoplastic causes (to correlate with pre -operative imaging), need for fusion (confirmed intra -operative instability) and intra-operative or postoperative complications.

E) Preoperative Clinical Evaluation Measures: All candidates were clinically examined preoperatively and postoperatively for comparative evaluation between the clinical condition preoperative and postoperative.

The Frankel Grade, according to the Congress of Neurological Surgeons, serves as a classification guide for spinal injuries. When a spinal cord injury occurs, patients were often told that they have an injury at a given spinal cord level and were given a qualifier indicating the severity of the injury, such as "complete" or "incomplete."

Frankel Grading system:

1. Complete neurological injury. No detected motor nor sensory functions below the level of the lesion.

2. The preserved sensation only. No detected motor function below the level of lesion with some preserved sensory function below the level of the lesion.

3. Preserved motor, nonfunctional. Some preserved voluntary motor functions below the level of the lesion but too weak to serve any useful purpose, sensation may or may not be preserved.

4. Preserved motor, functional. Functionally preserved useful voluntary motor function below the level of injury.

5. Normal motor function. Normal motor and sensory functions below the level of the lesion and abnormal reflexes may persist.

\section{Results}

\section{History Taking}

a) Sex: There were 36 males and 8 females $(4.5: 1)$, which shows male predominance by $81.8 \%$ (Figure 1A).

b) Age: Participants in this study ranged from 15 to 69 years old; the mean age was 48.3 years while the majority of patients, 22 cases. i.e. $50 \%$, were between 50 and 60 years old (the sixth decade) (Figure 1B).

c) Smoking: 32 cases $(72.7 \%)$ in this study were smokers, while 12 ones $(27.3 \%)$ were nonsmokers.

d) Trauma: Only 4 cases of our participants (9\%) gave us a history of preceding trauma in about 4 days, 6 days, 1 week and ten days before the onset of symptoms. There was no history of 
trauma in the other 40 cases (91\%).

e) Diabetes Mellitus: There was a history of diabetes in 14 cases $(31.8 \%)$. it was controlled in 6 cases $(13.6 \%)$ and uncontrolled in 8 cases $(18.2 \%)$ (Figure 1C).

No history of diabetes was given in 30 cases $(68.2 \%)$.

f) Hypertension: There was a history of hypertension in 20 cases $(45.4 \%)$, controlled in 8 cases $(18.1 \%)$ and uncontrolled in 12 cases $(27.2 \%)$. No history of hypertension in the other 24 cases $(54.4 \%)$.

\section{g) Malignancy:}

- 40 cases of our patients were proved to be metastatic tumours $(90 \%)$ classified as follows:

- 4 cases proved to be multiple myeloma

- 4 cases proved to be renal cell carcinoma (18\%).

- 8 cases with bronchogenic carcinoma

- 14 cases with hepatocellular carcinoma in origin (32\%). $(4.5 \%)$.

- 2 cases proved to be malignant lymphoma carcinoma $(4.5 \%)$.

- 2 cases with undifferentiated metastatic carcinoma $(4.5 \%)$.

- 2 cases proved to be spindle cell sarcoma

- 2 cases proved to be chondrosarcoma $(4.5 \%)$ and;

- In 8 cases of our patients, spinal epidural metastasis was the first presentation of malignancy (18\%) (Table 1), (Figure 1D).

Table 1: Summary of Patients Data

\begin{tabular}{lccc}
\hline Gender & Male & 36 & $82 \%$ \\
& Female & 8 & $18 \%$ \\
Trauma & Yes & 4 & $9 \%$ \\
Diabetes & No & 91 & $91 \%$ \\
Mellitus & Yes & 14 & $31.8 \%$ \\
Smoking & No & 30 & $68.2 \%$ \\
& Yes & 32 & $72.7 \%$ \\
Hypertension & No & 12 & $28.3 \%$ \\
\multirow{2}{*}{ Malignancy } & Yes & 20 & $45.5 \%$ \\
& No & 24 & $54.5 \%$ \\
& Yes & 40 & $91 \%$ \\
\hline
\end{tabular}

h) Systemic Infection: 4 cases of our patients $(9 \%)$ gave us history of respiratory tract tuberculosis and they also gave us history of receiving medical treatment of tuberculosis for about nine months. i) History of initial complaints and presentations:

- All our cases (100\%) gave us history of back pain varying in both sites, based on the site of the lesion, and severity, i.e how severe is the degree of spine affection.

- 40 cases were suffering from motor dysfunction (91\%).

- 24 cases were suffering from sensory dysfunction (55\%) and;

- 28 cases of our patients were suffering from sphincteric affection (64\%) (Figure 1E).

j) Clinical Evaluation:

- In this study, we found that back pain was the presented symptom in all our cases (100\%). Spine tenderness was also found in all cases $(100 \%)$ with variable sites according to the site of the lesion. Limb weakness was found in 40 cases $(91 \%)$, from which 4 cases $(9 \%)$ were suffering from both upper and lower limb weakness and 36 cases (82\%) were suffering from lower limb weakness with variable degrees from Grade 0 to Grade 4 motor power. Grade 0 was found in 8 cases (18\%), Grade 1 was also found in 8 cases (18\%), Grade 2 in 6 cases (14\%), Grade 3 in 12 cases $(27 \%)$ and Grade 4 was found in 6 cases $(14 \%)$. Sensory dysfunctions detected in 24 cases $(55 \%)$ of our participants.

- Sphincteric affection recorded in 28 cases $(64 \%)$ of our participants. 24 of these patients were suffering from urine and stool incontinence (55\%) and 2 cases were affected with urinary retention $(4.5 \%)$.

- 30 cases of our patients were suffering from hyperreflexia (68\%) while 14 cases were suffering from hyporeflexia (32\%) (Figure 1F).

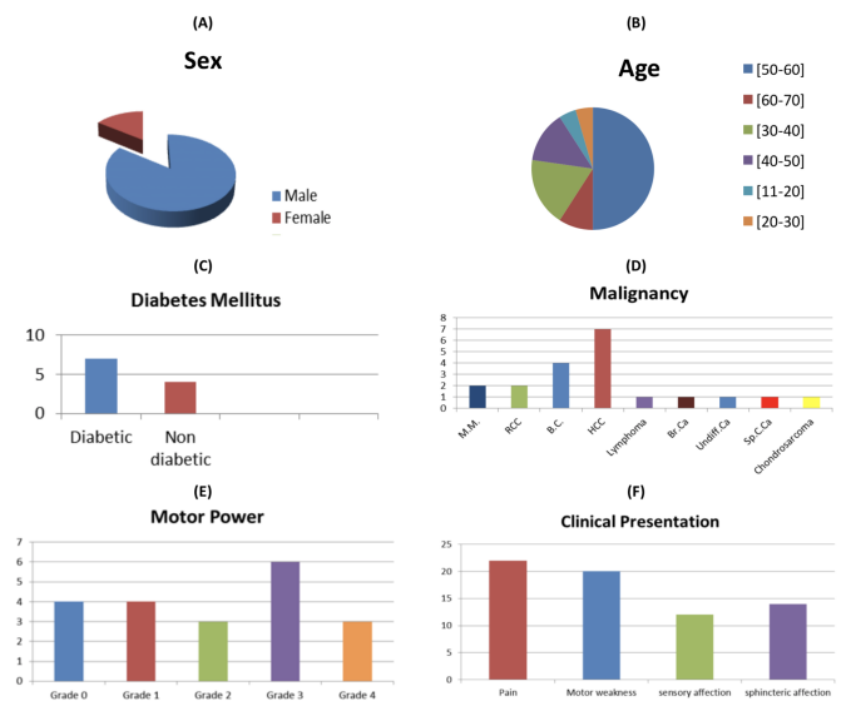

Figure 1: A), B), C), D), E), and F) Summary of Patients Data 


\section{Radiological Evaluation}

- All patients in this study were radiologically assessed by MRI over the affected sites of the spine.

- D10 was the commonest site to be affected in our study (23\%), followed by D5, D7, and then D12 which were affected in 6 of our cases $(14 \%)$. The dorsal spine was the most commonly affected spinal portion in our study, 26 cases $(59.1 \%)$, followed by lumbar spine in 12 cases $(27.3 \%)$, cervical spine in 4 cases $(9.1 \%)$, and then by sacrum in 2 cases (4.5\%) (Table 2$)$.

Table 2: Patients Radiological Findings

\begin{tabular}{llcc}
\hline Type of Investigation & Findings & No. of Patients & $\%$ \\
\hline & Lumbar & 26 & $59.1 \%$ \\
Site of lesion & Dorsal & 12 & $27.3 \%$ \\
& Cervical & 4 & $9.1 \%$ \\
Signs of instability & Sacral & 2 & $4.5 \%$ \\
Slippage at the same & Yes & 20 & $45 \%$ \\
or another level: & No & 30 & $68.1 \%$ \\
MRI Spine & Neoplasm & 40 & $91 \%$ \\
& Infection & 4 & $9 \%$ \\
\hline
\end{tabular}

- MRI revealed spinal metastasis in 40 participants with intraspinal extension and cord compression, while 4 cases $(9 \%)$ were affected by pott's disease.

- MRI of the spine also showed that none of our patients has any previous spine surgeries.

- Preoperative MRI, CT scans and Plain X -ray have shown the evidence of spinal instability in 20 cases $(45.5 \%)$, but intraoperative scans have revealed that 26 cases were unstable and were fixed (Figure 2).

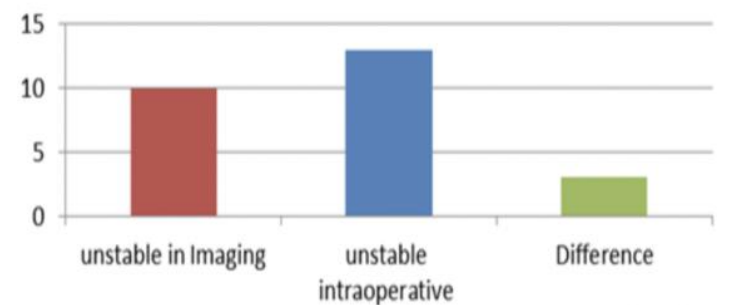

Figure 2: Difference between Radiological assessment and Intraoperative assessment of Instability

- Follow up CT scans and / or plain X-rays were done to all our cases in this study (Table 2).

\section{Surgical Intervention}

a) Preoperative:

The time interval between the first presentation and the operation ranges from 5 days to 150 days, mean of 26.22 days:

posterior approach.
- 4 cases (9\%) were operated through lateral thoracotomy.

- 2 cases of our participants (4.5\%), were operated by an anterior approach.

b) Intraoperative findings:

- 40 cases of our patients (91\%) proved to be neoplastic in origin and 4 cases ( $9 \%$ ) proved to be inflammatory (Abscess).

- 26 cases in this study (59.1\%) show evidence of instability and their need for fixation with decompression of the spinal cord together with tumor excision.

- 24 cases (54.5\%) were operated by decompressive laminectomy and transpedicular fixation, 4 cases of them (9\%) were unilaterally fixed on the left side only.

- 10 cases (23\%) were operated by decompressive laminectomy together with total mass excision.

- 4 cases (9\%) were operated by decompressive laminectomy only where there were no need for fixation.

- 2 cases of our patients (4.5\%) was operated by anterior corpectomy and pyra mesh insertion in a case of dorsal spine metastasis with no need for posterior fixation.

- 2 cases $(4.5 \%)$ was operated by anterior corpectomy with total mass excision and lateral plate insertion with screws.

- 2 cases $(4.5 \%)$ were operated by anterior corpectomy with total mass excision and expandable cage insertion.

c) Postoperative Outcomes:

All candidates in this study were postoperatively evaluated according to Frankel Grading system (A, B, C, D, and E) with the following outcomes:

- 22 cases $(50 \%)$ showed improvement of their condition from Frankel grade $\mathrm{C}$ to Frankel grade $\mathrm{D}$.

- 2 cases $(4.5 \%)$ showed improvement of their conditions from Frankel grade $A$ to Frankel grade $\mathrm{C}$.

4 cases $(9 \%)$ remained the same postoperatively as preoperatively with grade $\mathrm{C}$.

- 6 cases (13.6\%) remained the same postoperatively as preoperatively with grade $D$.

- 6 cases (13.6\%) remained same postoperatively as preoperatively with grade $A$.

- 4 cases of our patients (9\%) remained same postoperatively as preoperatively with grade $\mathrm{E}$ (Figure 3). 

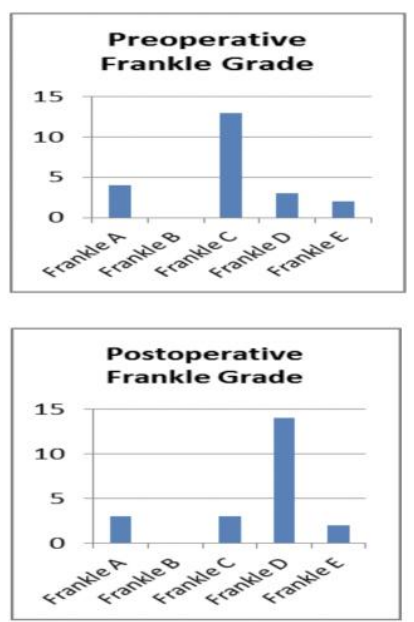

Figure 3: Comparison Between Preoperative \& Postoperative Frankel Grade

- All included participants in this study (100\%) showed an obvious improvement regarding pain and tenderness.

- Regarding motor power, 24 cases out of the 40 cases presented with the deterioration of their motor power $(55 \%)$ showed improvement of their motor power. However, 16 cases out of the 40 $(36 \%)$, did not show improvement with no further deterioration of these cases.

- Regarding sensations, 18 cases ( $41 \%$ ) out of the 24 presented with sensory dysfunction, showed marked sensory improvement. However, 6 cases

- (14\%) out of the 24 cases showed no improvement in their sensory dysfunction, but there was no further deterioration.

- Regarding sphincteric affection, only 6 cases $(14 \%)$ out of the 28 cases with sphincteric affection showed improvement, while the rest 22 cases $(50 \%)$ showed no improvement at all.

\section{d) Complications:}

- 6 cases of our patients (13.6\%) suffered from superficial wound infection for which they received intravenous systemic and local antibiotics for 14 days with total remission.

- 6 case $(13.6 \%)$ in this study was complicated by a dural tear from which one of them, the tear was accessible and directly repaired with sutures while for two other cases, the tears were inaccessible, so they were covered by muscle and gel foam. Both two cases were complicated by postoperative CSF leakage which stopped in one case spontaneously with medications and re -stitching the wounds while the other case stopped after insertion of a continuous lumbar drain for 5 days with total stoppage of CSF leak and complete wound healing.
Table 3: Summary of Neurosurgical Operations, Details And Outcomes

\begin{tabular}{|c|c|c|c|}
\hline \multicolumn{2}{|l|}{ Neurosurgery; Details and Outcomes } & $\begin{array}{c}\text { No. of } \\
\text { Patients }\end{array}$ & $\%$ \\
\hline \multicolumn{4}{|l|}{ Intraoperative Findings: } \\
\hline Instability & & 30 & $68.1 \%$ \\
\hline Canal stenosis & & 8 & $18.2 \%$ \\
\hline \multicolumn{4}{|l|}{ Operation: } \\
\hline Decompressive laminectomy only & & 4 & $9 \%$ \\
\hline $\begin{array}{l}\text { Decompressive laminectomy with mass } \\
\text { excision }\end{array}$ & & 10 & $22.7 \%$ \\
\hline \multicolumn{4}{|l|}{ Decompressive Laminectomy with } \\
\hline \multicolumn{3}{|l|}{ Unilateral mass excision } & $54.5 \%$ \\
\hline Bilateral mass excision & & 20 & $45.5 \%$ \\
\hline $\begin{array}{l}\text { Anterior corpectomy with mass } \\
\text { excision and pyra mesh insertion }\end{array}$ & & 2 & $4.5 \%$ \\
\hline $\begin{array}{l}\text { Anterior corpectomy with mass } \\
\text { excision and lateral fixation with plate } \\
\text { and screws }\end{array}$ & & 2 & $4.5 \%$ \\
\hline $\begin{array}{l}\text { Anterior corpectomy with mass } \\
\text { excision and expandable cage insertion } \\
\text { Complication: }\end{array}$ & & 2 & $4.5 \%$ \\
\hline $\begin{array}{l}\text { Dural tear directly } \\
\text { sutures }\end{array}$ & with & 2 & $4.5 \%$ \\
\hline Wound infection & & 6 & $13.6 \%$ \\
\hline CSF leak & & 2 & $4.5 \%$ \\
\hline
\end{tabular}

\section{Case Study}

\section{Case 1}

A 58-male patient, presenting with low back pain with tenderness, bilateral lower limb weakness, motor power grade 4 for about two weeks, intact sensations and intact sphincters. He gave us a history of bronchogenic carcinoma with brain metastasis two months before his

recent complaint, which was surgically removed. MRI dorsal spine showed D12 metastatic lesion which was operated by surgical decompression of the spine and unilateral transpedicular fixation of D10, 11, 12, L1, 2.

Postoperatively, the patient experienced marked improvement of back pain with the same motor power as preoperative (Figure 4).

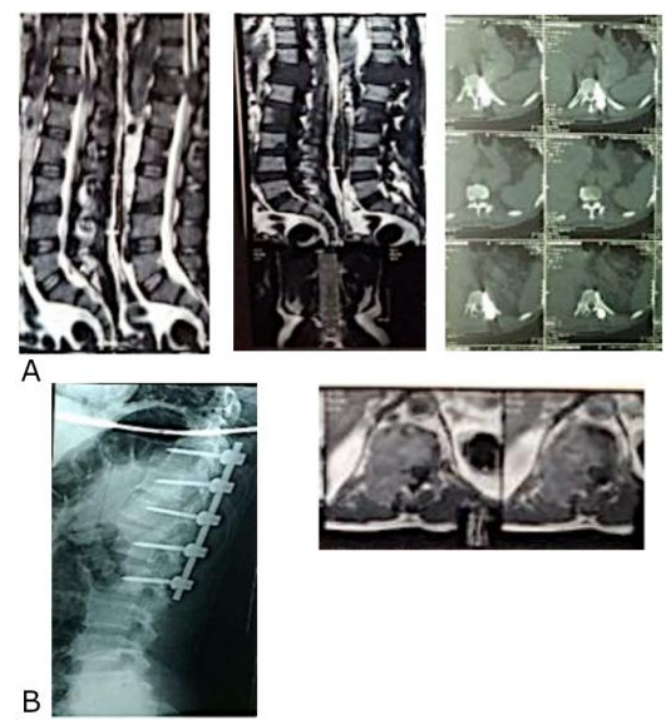

Figure 4: A) Preoperative Sagittal T1WI, T2WI and Axial T1WI; B) Postoperative Plain X-ray and Axial CT scan after fixation 


\section{Case 2}

A 49-male patient, presenting with severe back pain and tenderness with bilateral lower limb weakness grade 3 weeks, sensory level at xiphisternum, and urinary incontinence for two weeks' duration. MRI dorsal spine showed D8 metastatic lesion, which was operated through lateral thoracotomy by anterior decompression with the insertion of pyra mesh. Postoperatively, the patient showed improvement of sensory function and motor power as it became of grade 4 with regaining his urinary continence. Pathology revealed that the patient was suffering from plasma myeloma (Figure 5).

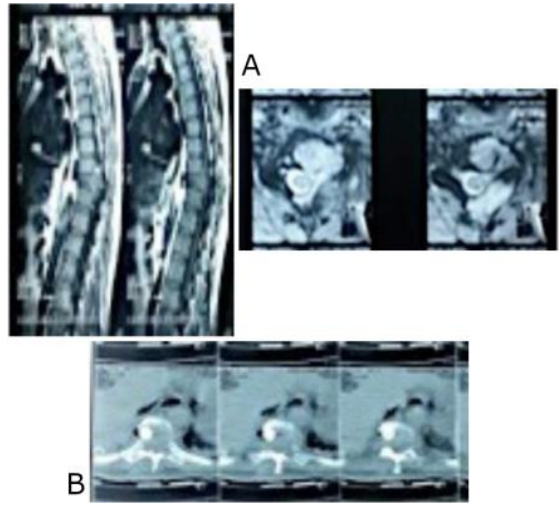

Figure 5: A) Preoperative Sagittal T1WI and Axial T2WI; B) Postoperative Axial CT scan after pyra mesh insertion

\section{Case 3}

A 29-male patient, presenting with back pain with tenderness, bilateral lower limb weakness of grade 2, the sensory level at the umbilicus, and urinary incontinence of 10 days' duration. MRI spine revealed D9 metastatic lesion, operated by lateral thoracotomy fixation with plate and screws together with decompressive laminectomy. Postoperatively, the back pain and tenderness were markedly relieved; motor power became of grade 4, sensory dysfunction improved, without improvement of sphincteric affection. Pathology was a high-grade spindle cell sarcoma (malignant peripheral nerve sheath) (Figure 6).

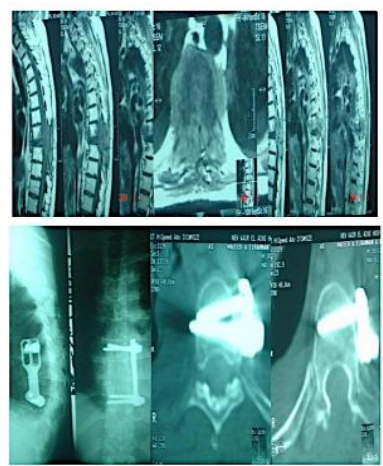

Figure 6: Preoperative Sagittal T1WI, Axial T1WI, and Sagittal T1WI with contrast Postoperative Plain X-ray Ap and lateral views and Axial CT scan post Fixation

\section{Case 4}

A 37 diabetic male patient presenting with back pain and tenderness, bilateral lower limb weakness of grade 3 , intact sensations and urinary incontinence for five months. MRI dorsolumbar spine showed L1 metastatic lesion, operated by decompressive laminectomy and fixation of D12 and L2. Postoperatively, the patient showed no improvement with the same motor power and urinary incontinence. Pathology revealed renal cell carcinoma which firstly presented with spinal metastasis (Figure 7).

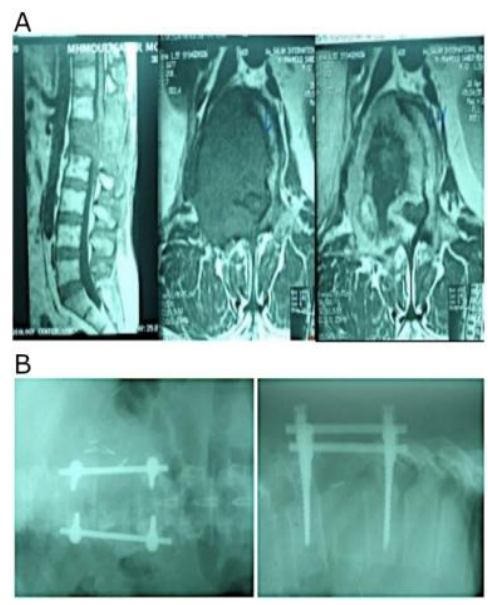

Figure 7: A) Preoperative Sagittal T1WI, Axial T1WI and Axial T1WI with contrast; $B)$ Postoperative Plain X -ray A $\ldots$ P and Lateral Views

\section{Case 5}

A 53-male patient, with a history of chronic renal failure, presented with back pain and tenderness, bilateral lower limb weakness grade 0 , hypothesis till the level of the umbilicus, and urinary and stool incontinence for about 12 days.

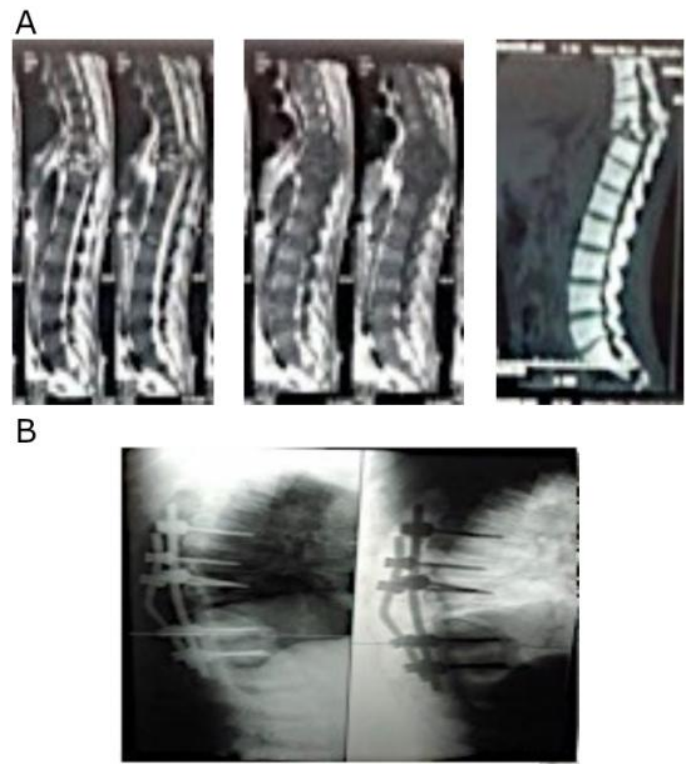

Figure 8: A) Preoperative Sagittal T1WI, Axial T1WI and Sagittal T1WI with contrast; B) Postoperative Plain X-ray Lateral and Axial views 
MRI Spine showed D10 metastatic spinal lesion, operated by decompressive laminectomy and transpedicular fixation of D8, 9, 11 and D12. Postoperatively, the motor power showed a minimal degree of improvement as it became of grade 1 and sensations slightly improved. However, there was no improvement of sphincteric affection. This case was complicated by dural tear and CSF leak which was repaired intraoperatively. The CSF leakage persisted for 2 days and treated conservatively under intravenous antibiotic coverage. Pathology revealed renal cell carcinoma (Figure 8).

\section{Discussion}

Patients with spinal epidural masses were complicated with spinal cord compression presented with back pain, sphincteric affection, motor and sensory dysfunctions.

Sensory affection in 24 cases $(55 \%)$ of our participants. Near the findings obtained by Bach et al., [2], were a retrospective study over 398 patients from 1979 to 1985 in which $83 \%$ of patients suffered from pain, $50 \%$ suffered from sphincteric affection, and around $70 \%$ suffered from motor dysfunction and only $10 \%$ was of normal sensations.

In this study, all patients were radiologically assessed by MRI over the affected side of the spine. D10 was the commonest site in our study to be affected in 10 cases of our participants $(23 \%)$, followed by D5, D7, and D12 each of them was affected in 6 cases $(14 \%)$, in another word spinal segments by order of frequency to be affected were dorsal followed by lumbar spine, these results were in agreement of the results of Jacobs WB et al., [3], [4], where a retrospective study over 282 patients was done from 1990 to 2001 for patients operated for neurological deficits due to thoracic and lumbar deficits and the patients with dorsal spine affection were $78 \%$ of the patients. 20 cases of our participant show signs of spinal instability and the need of spinal fixation (45.5\%), but intraoperatively 26 cases needed Spinal fixation (59.1\%) and 4 cases as operated through anterior approach by anterior corpectomy and replacement with pyra mesh in one case and with expandable cage in the other one (9\%), 14 cases $(31.8 \%)$ needed no fixation. MRI also revealed Spinal metastasis in 40 cases with intraspinal extension and cord compression, and 4 cases (9\%) were with pott's disease.

In the current study, we have performed decompressive laminectomy on 19 patients with spinal epidural masses together with mass excision as long as the tumour was accessible, with or without fixation. Fusion with instrumentation is indicated when postoperative segmental instability is inevitable after decompression or pre-existing instability is present or in the treatment of spondylodiscitis. Fixation with posterolateral fusion and instrumentation using rods and transpedicular screws was used in 12 patients $(54.5 \%), 10$ cases were detected preoperatively (45.5\%) and 2 cases $(9 \%)$ with inevitable instability due to aggressive bilateral medial facetectomy. By this technique we were able to stabilize the anterior and middle spinal columns as stated by Denis (Denis F et al., 1984), these results were also concluded by Klimo $P$, et al., [5], in which they concluded that posterior approaches have traditionally been the most common surgical procedure used for MSECC, with superior results for decompressive laminectomy combined with instrumentation of the spine.

All patients included in this study (100\%) showed an obvious improvement as regard pain and tenderness. This results are in agreement with that reported by Sundaresan et al., [6], [7], [8], [9], [10], [11], [12], a retrospective study over 110 patients and the results revealed $82 \%$ improvement regarding pain relief and ambulatory status. Also in Jansson et al., about $70 \%$ of their patients showed improvement of at least one Frankel grade compared to that in Weigel et al., [13], [14], in which a retrospective study was done over 76 patients, where there were $58 \%$ Frankel improvement in the ability to walk $93 \%$, and pain relief was noted in $89 \%$ of patients. Moreover, Wang et al., [15], a retrospective study over 140 patients in which there was the improvement of pain and improvement or stabilisation of their motor condition in $96 \%$ of their patients, and $75 \%$ of their patients regained the ability to walk again. Finally, in North et al., [16], [17], only $85 \%$ of patients were ambulatory preoperatively, and after surgery, about $97 \%$ were ambulatory.

The time interval between clinical presentation and surgical intervention revealed that the shorter the duration between them, the better were the results. Meanwhile, all cases reported improvement of pain and some cases reported improvement of their neurological deficit with the surgical interventions. These results in agreement with Michael et al., [18] as their results concluded that rapid diagnosis and emergency surgical treatment maximise neurological recovery. However, patients with complete neurological lesions or long-standing compression can improve substantially with surgery.

Table 4 summarises the suggested strategies to be followed with similar cases to our patients based on the clinical outcomes of the present study and the review of literature of the surgically treated patients with spinal epidural masses. 
Table 4: Suggesting a strategy for management of spinal epidural masses

\begin{tabular}{|c|c|c|c|c|c|}
\hline $\begin{array}{l}\text { Tumour } \\
\text { Localization }\end{array}$ & Approach & Tumour & $\begin{array}{l}\text { Reconst } \\
\text { ruction }\end{array}$ & Fusion & Option \\
\hline Cervical posterior & posterior & Complete resection & - & $\begin{array}{l}\text { Lateral mass } \\
\text { screws }\end{array}$ & \\
\hline Cervical anterior & anterior & Complete resection & $\begin{array}{l}\text { Cage or } \\
\text { bone }\end{array}$ & $\begin{array}{l}\text { Anterior } \\
\text { plating }\end{array}$ & $\begin{array}{l}\text { Lateral mass } \\
\text { screws }\end{array}$ \\
\hline $\begin{array}{l}\text { Cervicothoracic } \\
\text { junction posterior }\end{array}$ & posterior & Complete resection & - & $\begin{array}{l}\text { Lateral mass } \\
\text { +pedicle } \\
\text { screws }\end{array}$ & \\
\hline $\begin{array}{l}\text { Cervicothoracic } \\
\text { junction anterior } \\
\text { (good prognosis) }\end{array}$ & combined & Complete resection & Cage & $\begin{array}{l}\text { Lateral mass } \\
\text { +pedicle } \\
\text { screws } \\
\text { +anterior } \\
\text { plating }\end{array}$ & $\begin{array}{l}\text { Pedicle } \\
\text { screws }\end{array}$ \\
\hline $\begin{array}{l}\text { Thoracic } \\
\text { posterior }\end{array}$ & posterior & Complete resection & - & - & \\
\hline $\begin{array}{l}\text { Thoracic Anterior } \\
\text { (good prognosis) }\end{array}$ & combined & Complete resection & Cage & $\begin{array}{l}\text { Pedicle } \\
\text { screws }\end{array}$ & $\begin{array}{l}\text { Anterior } \\
\text { plating }\end{array}$ \\
\hline $\begin{array}{l}\text { Thoracolumbar } \\
\text { posterior }\end{array}$ & posterior & Complete resection & - & $\begin{array}{l}\text { Pedicle } \\
\text { screws }\end{array}$ & \\
\hline $\begin{array}{l}\text { Thoracolumbar } \\
\text { anterior (good } \\
\text { prognosis) }\end{array}$ & combined & Complete resection & cage & $\begin{array}{l}\text { Pedicle } \\
\text { screws }\end{array}$ & $\begin{array}{l}\text { Anterior } \\
\text { plating }\end{array}$ \\
\hline Lumbar posterior & posterior & Complete resection & - & 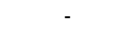 & $\begin{array}{l}\text { Pedicle } \\
\text { screws }\end{array}$ \\
\hline $\begin{array}{l}\text { Lumbar anterior } \\
\text { (good prognosis) }\end{array}$ & Combined & Complete resection & Cage & $\begin{array}{l}\text { Pedicle } \\
\text { screws }\end{array}$ & $\begin{array}{l}\text { Anterior } \\
\text { plating }\end{array}$ \\
\hline Sacrum & Posterior & $\begin{array}{c}\text { Complete or } \\
\text { subtotal resection }\end{array}$ & - & - & $\begin{array}{l}\text { Posterior } \\
\text { fusion }\end{array}$ \\
\hline
\end{tabular}

Spinal Epidural Masses are a heterogeneous group of patients with variable pathologies which can cause pain and irreversible loss of neurological functions. In most cases, this syndrome is caused by compression of the thecal sac and the spinal cord by these extradural masses.

The functional outcomes of surgical management for 44 patients with spinal epidural masses obtained from this study could be concluded as follows:

Spinal epidural masses were more common in males due to the higher incidence of malignancy and more exposure to environmental stresses.

The most common symptom was back pain and tenderness, and the most affected signs were motor weakness and sphincteric affection.

The time interval between the initial complaint until diagnosis and treatment correlated well with the outcomes. The earlier the diagnosis and treatment, the better the prognosis.

The sensitivity of $\mathrm{MRI}$ with contrast as verified by operative findings was found to be $100 \%$, and it proved to be the gold standard of treatment and the diagnostic tool recommended for more delineation, accuracy and specification.

The most presenting pathology was metastatic spinal cord compression. Most of the cases were operated by neural tissue decompression and tumour excision together with fixation.

The most common complications of these surgeries encountered in our study was superficial wound infection and dural tear complicated with CSF leak.

We found that all our patients experienced variables degrees of pain improvement, and most of our patients experienced improvement of motor weakness with variable improvement in sensory dysfunction.

Surgical intervention for spinal epidural masses has improved the quality of life for our patients.

It is widely accepted that the results of surgery regarding spinal masses, especially those with instrumentation, have superior results over the traditional surgery.

In conclusion, surgical intervention for spinal epidural masses can be very useful and successful as regard pain, motor power, sensations, and sphincteric affection. Patients have experienced a better quality of life and regained their ambulatory power which gave them the ability to resume activities in life.

\section{References}

1. Chhabra A, Batra K, Satti S, et al. Spinal Epidural Space: Anatomy, Normal variations, and pathological lesions on MR Imaging. Neuro--graphics. 2006; 5(1).

2. Bach F, Larsen BH, Rohde K, Borgesen SE, Gjerris F, Boge, Rasmussen T, Agerlin N, Rasmusson B, Stjernholm P, Sorensen PS. Metastatic spinal cord compression. Occurrence, symptoms, clinical presentations and prognosis in 398 patients with spinal cord compression. ActaNeurochir (Wien). 1990; 107:37-43.

https://doi.org/10.1007/BF01402610 PMid:2096606

3. Jacobs WB, Perrin RG. Evaluation and treatment of spinal metastases: an overview. Neurosurg Focus. 2001; 11(6):e10 https://doi.org/10.3171/foc.2001.11.6.11

4. Jacobs WB, Perrin RG. Evaluation and treatment of spinal metastases: an overview. Neurosurg Focus. 2001; 11:10. https://doi.org/10.3171/foc.2001.11.6.11

5. Klimo P, Dailey AT, Fessler RG. Posterior surgical approaches and outcomes in metastatic spine-disease. Neurosurg Clin N Am. 2004; 15(4):425-435. https://doi.org/10.1016/j.nec.2004.04.006 PMid: 15450877

6. Jansson KA, Bauer HC. Survival, complications and outcome of 282 patients operated for neurological deficit due to thoracic or lumbar spinal metastases. EurSpine J. 2006; 15:196-202. https://doi.org/10.1007/s00586-004-0870-6 PMid:15744540 PMCid:PMC3489401

7. Sundaresan $\mathrm{N}$ et al. Metastatic tumors of the spine. In Tumors of the Spine: Diagnosis and Clinical Management, 279-304 (Eds Sundaresan $\mathrm{N}$ et al.) Philadelphia: WB Saunders, 1990.

8. Sundaresan $\mathrm{N}$ et al. Surgery for solitary metastases of the spine: rational and results of treatment. Spine. 2002; 27:1802-1806. https://doi.org/10.1097/00007632-200208150-00021 PMid:12195075

9. Sundaresan $\mathrm{N}$ et al. Surgery for solitary metastases of the spine: rational and results of treatment. Spine. 2002; 27: 1802-1806. https://doi.org/10.1097/00007632-200208150-00021 PMid:12195075

10. Sundaresan N, Rothman A, Manhart K, Kelliher K. Surgery for solitary metastases of the spine: rationale and results of treatment. Spine. 2002; 27:1802-1806. https://doi.org/10.1097/00007632200208150-00021 PMid:12195075 
11. Sundaresan N, Scher H, DiGiacinto GV, Yagoda A, Whitmore $W$, Choi IS. Surgical treatment of spinal cord compression in kidney cancer. J Clin Oncol. 1986; 4(12):1851-6.

https://doi.org/10.1200/JCO.1986.4.12.1851 PMid:2431111

12. Sundaresan N, Boriani S, RothmanA,Holtzman R. Tumors of the osseous spine. J Neurooncol. 2004; 69:273-290.

https://doi.org/10.1023/B:NEON.0000041888.33499.03

PMid:15527096

13. Wang JC et al. Single--stage posterolateral transpedicular approach for resection of epidural metastatic spine tumors involving the vertebral body with circumferential reconstruction: results in 140 patients. J Neurosurg Spine. 2004; 1:287-298 https://doi.org/10.3171/spi.2004.1.3.0287 PMid:15478367

14. Wang JC, Boland P, Mitra N, Yamada Y, Lis E, Stubblefield M, Bilsky MH. Single--stage posterolateral transpedicular approach for resection of epidural metastatic spine tumors involving the vertebral body with circumferential reconstruction: results in 140 patients. J Neurosurg. 2004; 3:287-298.

https://doi.org/10.3171/spi.2004.1.3.0287 PMid:15478367

15. Weigel B, Maghsudi M, Neumann C, Kretschmer R, Muller FJ, Nerlich M. Surgical management of symptomatic spinal metastases: postoperative outcome and quality of life. Spine. 1999; 24:2240-2246. https://doi.org/10.1097/00007632-19991101000012 PMid:10562991

16. North RB, LaRocca VR, Schwartz J, North CA, Zahurak M, Davis RF, et al. Surgical management of spinal metastases: analysis of prognostic factors during a 10-year experience. $J$ Neurosurg Spine. 2005; 2(5):564-73. https://doi.org/10.3171/spi.2005.2.5.0564 PMid:15945430

17. North RB, LaRocca VR, Schwartz J, North CA, Zahurak M, Davis RF, McAfee PC. Surgical management of spinal metastases: analysis of prognostic factors during a 10-year experience. $J$ Neurosurg Spine. 2005; 2:564-573.

https://doi.org/10.3171/spi.2005.2.5.0564 PMid:15945430

18. Lawton MT, Porter RW, Heiserman JE, Jacobowitz R, Sonntag VK, Dickman CA. Surgical management of spinal epidural hematoma: relationship between surgical timing and neurological outcome. Journal of neurosurgery. 1995; 83(1):1-7. https://doi.org/10.3171/ins.1995.83.1.0001 PMid:7782824 